\title{
Particle Behavior During the Arc Spraying Process with Cored Wires
}

W. Tillmann, E. Vogli, M. Abdulgader, M. Gurris, D. Kuzmin, and S. Turek

\section{Erratum to: Journal of Thermal Spray Technology \\ DOI 10.1007/s11666-008-9272-3}

This article was mistakenly published without the following credit line:

This article is an invited paper selected from presentations at the 2008 International Thermal Spray Conference and has been expanded from the original presentation. It is simultaneously published in Thermal Spray Crossing Borders, Proceedings of the 2008 International Thermal Spray Conference, Maastricht, The Netherlands, June 2-4, 2008, Basil R. Marple, Margaret M. Hyland, Yuk-Chiu Lau, Chang-Jiu Li, Rogerio S. Lima, and Ghislain Montavon, Ed., ASM International, Materials Park, OH, 2008.

The online version of the original article can be found under doi:10.1007/s11666-008-9272-3.

W. Tillmann, E. Vogli, and M. Abdulgader, Institute of Materials Engineering, Dortmund University of Technology, LeonhardEuler-Str. 2, 44227 Dortmund, Germany; and M. Gurris, D. Kuzmin, and S. Turek, Institute of Applied Mathematics, Dortmund University of Technology, Vogelpothsweg 87, 44227 Dortmund, Germany. Contact e-mail: wolfgang.tillmann@udo. edu. 